\title{
LOS CONTROVERTIDOS LÍMITES DE LA DIFERENCIA ESPECÍFICA EN EL SEGUNDO ENUNCIADO LEXICOGRÁFICO
}

\author{
THE LIMITED CONTROVERSIES OF THE SPECIFIC DIFFERENCE IN THE SECOND \\ LEXICOGRAPHIC STATEMENT
}

\author{
M. a Auxiliadora Castillo Carballo \\ Universidad de Sevilla \\ auxicastillo@us.es
}

Recibido: 04/05/2017

Aceptado: 24/07/2017

\begin{abstract}
Resumen
Elaborar una definición lexicográfica no es una tarea fácil, sobre todo porque, al margen de la técnica que se desarrolla para configurar y acotar una realidad concreta, se deben tener en cuenta las expectativas del destinatario del repertorio léxico, aunque sin incurrir en excesos informativos que resulten superfluos o desorienten en la correcta interpretación de lo que se dice. Habitualmente, se considera que no solo basta con elegir el hiperónimo acertado, sino que las diferencias específicas no deben contravenir el modelo del diccionario de lengua, en el que se espera que se aporte a través del segundo enunciado la información justa de las entradas para que queden claramente delimitadas. En todo caso, resulta complejo establecer compartimentos estancos entre lo lingüístico y lo extralingüístico, pues, a veces, puede ser contraproducente eludir la información referente a las cosas, ya que la finalidad de la definición no es otra que la de ayudar al usuario a captar el contenido del vocablo que se parafrasea.

PALABRAS CLAVE: lexicografía, diccionario, definición lexicográfica, segundo enunciado, diferencia específica.
\end{abstract}

\begin{abstract}
The task of elaborating a lexicographic definition is not easy, above all because, aside from the technique that is developed to configure and define a concrete reality, the expectations of the recipient of the lexical repertoire must be considered, although should be avoided incurring informative excesses that are superfluous or disorient in the correct interpretation of what is said. Usually, choosing the correct hyperonym is not enough, but the specific differences should not contradict the model of the language dictionary, in which it is expected that the fair information of the entries for a clear delimitation will be provided by mean of the second statement. In any case, it is complex to establish tight compartments between the linguistic and the extra-linguistic, because sometimes it can be counterproductive to avoid information concerning things, since the purpose of the definition is to help the user to understand the content of the word that is paraphrased.

KEYWORDS: lexicography, dictionary, lexicographical definition, second statement, specific difference.
\end{abstract}

Para citar este artículo / To cite this article: Castillo Carballo, M. ${ }^{a}$ Auxiliadora (2017). Los controvertidos límites de la diferencia específica en el segundo enunciado lexicográfico. ELUA, 31: 117-134. doi: 10.14198/ELUA2017.31.06

Enlace / Link: http://dx.doi.org/10.14198/ELUA2017.31.06 


\section{INTRODUCCIÓN}

En el ámbito de la praxis lexicográfica, desde el momento en que se procede a establecer deslindes categoriales en el continuo de la lengua comienza a comprenderse la necesidad de facilitar al usuario del diccionario la consulta de las distintas informaciones, por más que se sea consciente de que nos encontramos con un proceso de abstracción que deja al margen aspectos muy diversos. Esto afecta, qué duda cabe, a la propia selección de las piezas léxicas que componen el repertorio y, por supuesto, a la información referente a cada una de ellas, en los dos enunciados microestructurales pertinentes (Seco 1987). Así, por ejemplo, es comprensible que la marcación de las diferentes unidades, referente a su inclusión en una determinada lengua funcional o a su comportamiento pragmático, obedece a necesarias simplificaciones, por lo que se dejan a un lado variaciones discursivas poco homogéneas. Es decir, nos encontramos con tendencias de uso derivadas de la consulta de corpus que se consideran suficientemente representativos.

Las múltiples particularidades a las que se enfrenta la catalogación lexicográfica no son óbice para establecer una síntesis susceptible de modificarse con el tiempo. Esto implica una visión del repertorio lexicográfico general como un producto que refleja un estado de lengua, en una cultura determinada y orientado a los intereses concretos de un conjunto limitado de usuarios. Así, si se considera que el contenido macroestructural no supone un reflejo de la totalidad de voces de una lengua viva y que la no sanción lexicográfica no indica la inexistencia e incluso la normalidad de uso, pues existen convenciones que justifican ciertas decisiones, hay que colegir que una catalogación orientada a un público no especializado puede dejar insatisfecho al morfólogo, que busca coherencias basadas en la regularidad léxica, y al semántico, que pretende ver la plasmación del contenido significativo de los signos que forman parte de un sistema de valores puros. Pero conviene incidir en la idea de la simplificación informativa, pues, del mismo modo que, por poner un ejemplo, el dialectólogo no va a vislumbrar en un diccionario general de lengua una precisión rigurosa en las informaciones de marcación diatópica dentro del primer enunciado estructural (el que alude a la entrada en cuanto signo), no es exigible un análisis sémico inmanente en el segundo (Seco 1987), ya que no nos encontramos con obras orientadas a especialistas que buscan satisfacer los recurrentes anhelos del reflejo de una escuela lingüística, sino con productos que muestran un estado de lengua y que constatan habitualizaciones de expresión y contenido, es decir, usos consolidados. No podemos olvidar que el diccionario es un producto comercial, entendido desde un punto de vista no peyorativo (Quemada 1987; Climent de Benito 2007), lo que va a determinar no pocas decisiones que hay que tomar en su confección. Si a esto le añadimos que desde sus orígenes se trata de obras con una finalidad esencialmente pedagógica (Dubois 1971; Rey 1989), debemos concluir que se necesita establecer prioridades más allá de imposiciones estrictamente lingüísticas:

Es cierto que pueden distinguirse en los signos lingüísticos rasgos más relacionados con las reglas sintácticas o semánticas de la lengua (argumentos, colocaciones, relaciones sinonímicas, etc.) y rasgos más relacionados con las cuestiones referenciales y pragmáticas (marcas, connotaciones, etc.); pues bien, todas esas características forman como los hilos de un cordón, la unidad lexicográfica de la lengua. La decisión de que aumenten o reduzcan su presencia en un diccionario es más una cuestión de proyecto editorial, de presupuesto, de límites físicos del diccionario que de cuestiones teóricas. En definitiva, la 
decisión de cargar más o menos notas de las llamadas enciclopédicas en un diccionario es una decisión pedagógica de acuerdo con una decisión empresarial, no tiene nada que ver con la esencia de la definición ni del diccionario (Gutiérrez Cuadrado 2008: 527).

En el ámbito definicional el problema reside en la imposibilidad de abarcar los múltiples matices de contenidos asociados a un vocablo. Incluso resulta difícil discriminar la información necesaria que impida la confusión entre piezas léxicas sin caer en hiperespecializaciones que en nada favorecen la comprensión de lo parafraseado. De hecho, se dan casos en los que, en un artículo perteneciente a un repertorio general de lengua, se incluyen definiciones enciclopédicas, mientras que en un diccionario enciclopédico se perciben artículos con paráfrasis definicionales consideradas estrictamente "lingüísticas", es decir, las que son susceptibles de descomponerse en rasgos sémicos tenidos por "no superfluos". Pero al margen de esta lógica constatación, conviene subrayar que en el metalenguaje empleado, también en los diccionarios enciclopédicos, ha de tenerse en cuenta que lo que va a predominar es la definición divulgativa y que incluso la estrictamente científica se va a valer de unidades ubicadas en el estándar léxico (Anaya Revuelta 1999-2000). En todo caso, nos encontramos ante información puntual, nunca global ${ }^{1}$, al tratarse de herramientas útiles para una consulta rápida ${ }^{2}$.

Es una constante recurrir en las perífrasis definicionales a la tradicional diferenciación entre género próximo y diferencia específica. Al margen de los problemas de acertar o no con la elección del hiperónimo clasificador, lo que nos interesa es preguntarnos cómo delimitar la información añadida para establecer la distinción con otras unidades designadoras de realidades que pueden presentar no pocas similitudes, con el fin de establecer la identidad de la pieza léxica (Tesso 1987). Es en la propia eficacia de la consulta donde el lexicógrafo ha de poner todos sus esfuerzos, al margen de dogmas metodológicos, debidos, en gran parte, a lo establecido por la tradición lexicográfica ${ }^{3}$ o a las aportaciones de las distintas escuelas lingüísticas, que dificulten una labor de por sí complicada. Resulta interesante, en ese sentido, abordar las tendencias definicionales de algunos diccionarios sincrónicos del español de mayor difusión, incluido los académicos. Evidentemente, para este cometido han de estar muy presentes los repertorios de orientación didáctica. El objetivo no es otro que comprobar la flexibilidad o rigidez en el llamado segundo enunciado microestructural y reivindicar una mayor coherencia en su configuración.

\section{INFORMACIÓN LINGÜÍSTICA E INFORMACIÓN EXTRALINGÜÍSTICA}

La verbalización del sentido consolidado ha de satisfacer, también se ha dicho más arriba, las necesidades del lector, que no necesariamente busca una constatación exacta de los deslindes del sistema lingüístico que se refleja. Es decir, si bien resulta deseable, como se ha

\footnotetext{
1 La necesidad de elaborar definiciones inteligibles para el usuario se intensifica en el campo cientificotécnico, y muy especialmente cuando se abordan los llamados neónimos, entendidos como términos, voces de especialidad, de nueva creación o, al menos, de reciente incorporación al léxico general, ya que el dinamismo en el léxico implica no pocos trasvases entre lenguas funcionales. En todo caso, el hecho de que el lector no esté totalmente familiarizado con estas piezas léxicas requiere de una banalización (García Platero 2015: 103-129), que no ha entenderse, ni mucho menos, de forma peyorativa, sino como un esfuerzo de accesibilidad a determinados contenidos, teniendo muy en cuenta que el destinatario del artículo lexicográfico no es un erudito en la materia.

2 De gran interés resultan los planteamientos sobre teoría lexicográfica defendidos por Tarp (2003, 2008, 2013).

3 De hecho, se ha hablado del diccionario como género literario (Abad Nebot 1999; García Ibáñez 2001).
} 
insistido en más de una ocasión en metalexicografía, distinguir, en la medida de lo posible, lo que atañe al signo lingüístico de lo que corresponde a la cosa nombrada, sobre todo porque la información referente a esta última es más susceptible de soportar una mayor carga ideológica, no siempre es pertinente establecer deslindes tajantes que en nada contribuyen a cumplir con las funciones que tiene encomendadas el diccionario.

Conviene tener presente que, al margen, de los elementos lingüísticos y extralingüísticos que conforman la verbalización de un sentido, también tienen cabida otros complementarios, pero no menos necesarios, porque inciden en aspectos contextuales. No obstante, cualquier elemento contextual que esté presente en una definición lexicográfica no es parte del llamado contorno, pues este solo hace referencia al contexto argumental de la palabra definida (Porto Dapena 2014: 192). Es decir, la catalogación de un vocablo en el diccionario no solo atiende a los semas internos, que se materializan mediante una paráfrasis, sino también a los que condicionan su combinabilidad, que se actualizan en el contorno definicional, y se consideran imprescindibles en el funcionamiento sintagmático del definido (Porto Dapena, 2014: 195-196). Por lo tanto, lo que está relacionado con los contextos referenciales, que relacionan la entrada con la realidad a la que se refiere, los tropológicos (o usos figurados, amplios, restringidos, irónicos, humorísticos), los contextos geográficos, cronológicos, diastrático-diafásicos, de usuarios o indicación de quienes con exclusividad utilizan la palabra que se define, de especialidad y temático quedan fuera del concepto de contorno, y se le ha llamado entorno (Porto Dapena 2014: 235-263), que, aunque se presenta como enunciado independiente de la definición, pero inserto en el enunciado lexicográfico, puede expresarse también mediante el sistema de marcación habitualizado y que se corresponde con el llamado primer enunciado lexicográfico al que hizo alusión Seco (1987). De este modo, los contextos argumentales poseen la peculiaridad de que pueden formar parte de la definición, aunque no en todos los casos. Es decir, es posible que la paráfrasis resulte insuficiente por sí misma y necesite del contorno para atender con precisión al sentido del definido, por lo que difícilmente se podría establecer compartimentos estancos entre la paráfrasis y el contorno. Si bien el entorno nunca funciona como un elemento constitutivo del sintagma definicional y es, lógicamente como se ha señalado, un enunciado independiente. En ese sentido, habría que advertir que, en ocasiones, se detectan acepciones que en su totalidad no son más que un mero contexto y no una definición.

Es cierto que en el léxico hay estructuraciones desde la lengua y simples ordenaciones de acuerdo con condicionamientos que están fuera de ella. En este último caso, la significación concuerda con la designación, frente a lo estrictamente sistemático (Coseriu 1977), aunque hay que incidir en la falta de deslindes:

En realidad, no se llegará a establecer los límites precisos entre lo que está estructurado explícitamente en el léxico. Pero lo importante es que se reconozca que, en el léxico de una lengua, hay unas parcelas puramente designativas cuya estructuración posible es la enumeración o, en su caso, la ordenación; y otras que están estructuradas desde la lengua: hay, como afirma Coseriu, un léxico estructurado lingüísticamente y un léxico nomenclador (Escobedo Rodríguez 1999).

Pero una cosa es el reconocimiento de lo que, en efecto, pertenece a la delimitación de las unidades en la realidad objetiva frente a la intuición de esa realidad y otra explicitar lo 
que ha de formar parte de la verbalización lexicográfica de las piezas léxicas ubicadas en uno u otro bloque. Incluso la extendida separación entre los rasgos inherentes y aferentes, propuesta por Rastière $(1987,1991)$ a partir del concepto de virtuema de Pottier (1977), dependiente de las experiencias socioculturales de los hablantes, no está tan clara, ya que "un rasgo puede ser inherente dentro de una lengua funcional, y aferente en otra" (Anaya Revuelta 1996: 71). Dicho de otro modo, la inestabilidad debida al carácter virtual e individual de un rasgo sémico puede estabilizarse al alcanzar un estatuto social y genérico, de ahí que sea discutible su eliminación a la hora de establecer discriminaciones en las perífrasis definicionales. Esto no es impedimento para que, en no pocas ocasiones, se incluyan rasgos de hiperespecialización, que en nada ayudan a conseguir una visión prototípica de la realidad designada, imprescindible para facilitar el conocimiento del término que se intenta definir (Bosque 1982: 112).

Se aludió antes a la inamovilidad a la hora de establecer el esquema definicional sin tener presente el tipo de usuario, pues se suele acudir a la suficiencia especificadora como un axioma que cualquier lexicógrafo es capaz de aprehender de forma sistemática:

No obstante el buen sentido -el sentido común- lingüístico y cultural es el que debe optar en cada definición por delimitar lo que resulta imprescindible léxicamente y lo que es ya añadido enciclopédico; esta tarea no se puede llevar a cabo mediante procedimientos informáticos, sino con el talento y el esfuerzo (un esfuerzo muy pesado y que requiere lentas horas) de los estudiosos (Abad Nebot 1999: 51).

Sin embargo, en el fondo se claudica ante lo inevitable, porque quien define tiene a su disposición un número importante de datos que ha de conectar metalingüísticamente y queda a su merced la selección de lo que se va a plasmar; y el sentido común es más que discutible. Se ha de tener, además, en cuenta, al menos en teoría, la clase de catalogación léxica a la que se enfrenta, pues el destinatario va a condicionar las actuaciones. Existe toda una tradición que se abraza de forma mecánica y parece allanar el camino ante el difícil reto de tomar decisiones, $\mathrm{y}$, por supuesto, también existe la confianza ciega en la intuición del lexicógrafo, pues parece que en todo momento será capaz de darle entidad a la supuesta suficiencia de la diferencia específica. Se ha distinguido, incluso, lo suficiente — que teóricamente se consigue cuando se cubren todos los empleos posibles de la pieza léxica, por lo que se excluyen los no posibles ${ }^{4}$ — de lo imprescindible — pues si se retira uno de los componentes definicionales se pierde cualquier atisbo de distintividad- (Dagenais 1985: 58). Pero cualquier aproximación teórica no exenta de racionalidad se da de bruces con la praxis, pues, como se acaba de indicar, el lexicógrafo tiene la responsabilidad de establecer una selección sémica difícilmente objetivable, aunque sí podría tenerse en cuenta una serie de pautas que permita conjugar la aproximación necesariamente estereotipada a la entidad a la que se alude con la función codificadora que ha de preservarse en cada uno de los

4 Lo que entra precisamente en contradicción con la idea de Trujillo (1994: 82) cuando afirma que "al limitar lo semántico a la definición de objetos designables y no de significados, y a unas reglas de combinación de acuerdo con las condiciones mismas de lo designable, el diccionario suprime la información que permite, en la práctica real del idioma, efectuar combinaciones no dadas antes e incluso prohibidas por esa misma razón, y elegir designaciones no previstas tampoco hasta el momento en la práctica común". Según esta perspectiva, habría que tener en cuenta no solo lo suficiente y lo imprescindible, sino también lo previsible, lo que complicaría, qué duda cabe, la labor del lexicógrafo, pues se exige unas intuiciones de comportamiento semántico difícilmente objetivables. 
enunciados lexicográficos, mermando, además, las veleidades subjetivas, al menos las que conducen a una determinada cosmovisión no pocas veces criticada (Rodríguez Barcia 2016), de ahí que por encima de supuestas suficiencias habría que hablar de aceptabilidades, que vienen dadas por su "inteligibilidad, claridad y orden" (Gutiérrez Cuadrado 2010).

Son muchos los que se rebelan ante el conocido deslinde entre el conocimiento lingüístico y el cultural. A ello se refirió en su día Bosque (1982: 114-115) al destacar, por suficientemente extendida, la opinión de Haiman (1980), que se refiere a la imposibilidad de distinguir lo que un diccionario ha de decir sobre una palabra de lo que debe explicitar una enciclopedia sobre el objeto nombrado por esa palabra. Por ello, puede colegirse que la definición lexicográfica es de carácter enciclopédico, aunque arbitrariamente abreviada ${ }^{5}$. Defiende Bosque que esta reflexión no es óbice para que en muchos casos sea posible separar la descripción del objeto de la definición del vocablo, pues se dan oposiciones estrictamente semánticas, como ocurre, por ejemplo, con dinero y moneda o vecindario y vecino, basadas en los rasgos de continuidad y no continuidad o en los de colectividad e individualidad respectivamente. Pero no puede caerse en la tentación de confundir, conviene incidir en ello, intereses muy distintos. Si son aplicables determinados esquemas definicionales basados en oposiciones sémicas, no resultan prescindibles, en modo alguno, las referencias al ámbito de lo extralingüístico, porque no estamos hablando de significados léxicos, sino de sentidos ocasionales, lo que encuentra parangón con las realizaciones fonemáticas. De hecho la mayor parte de las definiciones pueden considerarse "lexipédicas", pues se constatan rasgos pertenecientes tanto a las definiciones enciclopédicas como a las léxicas (Gutiérrez Cuadrado 2008), Es decir, no es un problema semántico la selección de rasgos denotadores o connotadores en el ámbito de las paráfrasis definicionales, porque estamos hablando de esferas e intereses bien distintos:

Denotaciones y connotaciones no son más que acontecimientos que pueden ser abarcados por el significado de los signos: entidades conceptuales o físicas, pero jamás significados, ya que éstos no pueden confundirse con el hecho de que en nuestra vida cotidiana solamos referir el significado de las expresiones a nuestra experiencia de la realidad o, peor aún, a lo que cada cual entiende por "realidad" (Trujillo 1984: 29).

Se puede colegir que lo que tantas veces ha criticado el semantista se convierte en una característica distinguidora del producto lexicográfico exigible por el usuario, por muchas carencias que se intenten enumerar. Por lo tanto, nos encontramos con obras que se valen de otras disciplinas para sus fines utilitarios, nacen con fecha de caducidad y se convierten en reflejos de un tiempo y una época determinados. La semántica, evidentemente, ha contribuido a la evolución de la lexicografía práctica, pero no se puede "tratar de identificar definición lexicográfica y significado, pues la definición sólo es una de las posibles interpretaciones del significado de la palabra, y es la semántica la que legítimamente puede describir el sistema léxico: las realizaciones de ese sistema son las que registra el lexicógrafo" (Hernández 1989-90: 177).

5 La propia Academia en el DRAE de 1992 reconoce en el prólogo que, aunque el diccionario no pretende ser una enciclopedia abreviada, se considera pertinente sancionar y definir los términos que rebasan los límites de especialidad, debido al poder sociodifusor de los medios de comunicación y a su uso en la conversación culta. 


\section{LA FLEXIBILIDAD DEFINICIONAL}

Aunque se ha reflexionado, en no pocas ocasiones, sobre la impotencia que puede experimentar el lingüista estructural al no ver reflejado con nitidez los principios básicos de su pensamiento en el diccionario, pues los condicionamientos van a mitigar demasiadas expectativas, conviene recordar que si bien en el plano de la expresión el establecimiento de unos rasgos opositivos que expliciten el estatuto funcional de las diferentes unidades resulta factible, en la medida en que son limitadas las piezas que entran en juego, el acercamiento al contenido no ha estado nunca exento de obstáculos, por razones obvias. El principal de ellos estriba en la aplicación de un método objetivo que deje al margen cualquier atisbo de selección azarosa de lo extralingüístico. El deslinde de contenidos implicaría para algunos un acercamiento inmanente que impida cualquier intromisión de lo extralingüístico en un sistema de valores puros, pero si atendemos a esta necesidad en el quehacer del lexicógrafo, las dificultades son insalvables. Dicho de otro modo, es posible, sin lugar a dudas, establecer invariantes de expresión, en la medida en que los particularismos discursivos quedan al margen de cualquier catalogación, al menos de carácter genérico, pero no ocurre lo mismo cuando nos centramos en el significado, de ahí la necesaria recurrencia al sentido, entendido como variante contextual. Y en la medida en que el diccionario general refleja empleos de consenso, solamente se va a catalogar lo que se considere suficientemente consolidado en una sincronía dada, es decir, la acepción, no tan inefable como el significado. Por ello, las críticas centradas en que el diccionario solamente mira al pasado, pues no refleja la potencialidad del signo catalogado, resultan válidas solo si se considera que estamos ante una sistematización de unidades en una lengua funcional (Trujillo 1994, 1995). Sin embargo, no parece que en la elaboración de la planta de un diccionario se piense en un objetivo en nada exigido por el usuario, aunque ciertamente sugerente para el lingüista, como es el de diferenciar las invariantes de contenido de los empleos discursivos $^{6}$. Y no se trata de mirar al pasado, lo que casaría poco con la consideración sincrónica de la mayor parte de las obras lexicográficas, sino de constatar unos empleos discursivos generalizados. De hecho, se ha dicho, con razón, que el llamado diccionario de lengua es antes que nada un repertorio del discurso, pues las perífrasis definicionales vienen motivadas por empleos contextuales de carácter sintáctico y léxico, en la medida en que se tienen en cuenta acepciones marcadas, por ejemplo, por el carácter transitivo o intransitivo de una forma verbal, de ahí que se afirme que en el artículo lexicográfico nos encontramos con "una reescritura del enunciado que nos sirve de base para la descripción lexicográfica de un uso" (Ahumada 2006: 17).

En los diccionarios no se confunde el significado con el uso, porque solamente se incluye lo ya consolidado de acuerdo con unos hábitos suficientemente corroborados en las fuentes documentales. El reflejo de esa norma mutable implica la recurrencia a cuantas informaciones se consideren útiles para la correcta comprensión de estos consensos, prescindiendo

\footnotetext{
6 Es evidente que los diccionarios llegan a coartar la posibilidad de innovación expresiva y conceptual, pues "acorralan al hablante en un sector muy estrecho del sistema respecto de las posibilidades que le brinda" (Hernández 1989-90: 175), por lo que resultan necesarias no pocas reformas, pero otra cosa es que, argumentado incluso que impide la codificación textual, se abogue por una paráfrasis sugeridora de la dirección significativa de la pieza léxica (Trujillo 1994), pues no parece que sea un proceder que satisfaga sin complicaciones las exigencias del usuario, en la medida en que no se diferencie con claridad lo habitualizado de las potencialidades de uso, sobre todo porque no siempre es factible establecer previsiones y mucho menos verbalizarlas.
} 
de datos que no estén orientados para este fin. Por ello, no ha de resultar, en modo alguno, desaconsejable la presencia, si así se requiere, en función de casuísticas muy variadas, de definiciones de carácter descriptivo-identificativo, no necesariamente opositivas, en las que la señalada delimitación entre lo lingüístico y lo enciclopédico no se percibe con claridad (González Pérez 1992: 94). No es, en absoluto, rechazable la definición ostensiva, pues incide en esta necesidad identificadora del contenido de determinados vocablos. Este procedimiento, del que no faltan ejemplos a lo largo de los años ${ }^{7}$, permite hacer inteligible lo que, por sus especiales características, resulta complejo de parafrasear. La querencia académica por este tipo de definiciones es evidente:

azul

1. adj. Dicho de un color: Semejante al del cielo sin nubes y el mar en un día soleado, y que ocupa el quinto lugar en el espectro luminoso.

$\left(D L E^{8} 2014\right)$

\section{naranja}

[...] 4. adj. Dicho de un color: Semejante al de la naranja madura, y que ocupa el segundo lugar en el espectro luminoso. U. t. c. s. m.

(DLE 2014)

verde

1. adj. Dicho de un color: Semejante al de la hierba fresca o al de la esmeralda, y que ocupa el cuarto lugar en el espectro luminoso.

(DLE 2014)

Frente a esto, es destacable que algunos diccionarios que parecen buscar con mayor énfasis la inteligibilidad definicional no sean sistemáticos en el mecanismo ostensivo:

\section{azul}

adj.inv./s.m.

1 Del color del cielo cuando está despejado: El azul es el quinto color del arcoíris y está situado entre el verde y el añil.

(Diccionario CLAVE 2012 )

\section{naranja}

adj.inv./s.m.

1 Del color que resulta de mezclar rojo y amarillo. anaranjado.

(Diccionario CLAVE 2012)

verde

adj.inv.

[...] 12 Del color de la hierba fresca.

(Diccionario CLAVE 2012)

7 Ya en el Diccionario de Autoridades (1726-1739) se acudía a este tipo de definiciones en el caso de los colores, sin aludir al lugar que ocupan en el espectro luminoso.

8 Última edición del Diccionario académico en su versión impresa.

9 CLAVE. Diccionario de uso del español actual. 
Obviamente, los autores de diccionarios no deben optar de forma exclusiva por inferencias de disciplinas que tienen objetivos bien diferentes, como tampoco han de ser víctimas de dogmas metalexicográficos inquebrantables, como el cumplimiento de la ley de sustituibilidad entre la definición y el definido ${ }^{10}$, pues la inteligibilidad del enunciado exige necesarias flexibilidades. No se trata de nada nuevo, ya que los distintos métodos de verbalización de los sentidos consolidados apuestan por el valor codificador y descodificador del ejemplo o por la defensa de la definición frástica", que "no es una perífrasis, no es un sinónimo de la entrada y no expresa su función", por más que integre la información semántica referente al sujeto o al complemento sin recurrir a ninguna marcación tipográfica (Rey-Debove 1994: 39). No resulta raro encontrar este tipo de definición en catálogos de orientación didáctica.

abrupto, -a 1 adj. Un terreno abrupto tiene rocas, cortes o pendientes muy pronunciadas y, por ello, es difícil caminar por él: Burló a los que le perseguían por aquellos lugares abruptos e intransitables.

(Diccionario Estudio Salamanca. Secundaria y bachillerato. Octaedro 2007).

campear $1 v$. Un animal campea cuando anda libre por el campo: Por la ladera campeaba un rebaño de cabras. $2 v$. Una persona o una cosa campean si sobresalen entre otras: En la cara del sur campea [...] la imagen barroca del santo mártir.

(Diccionario Estudio Salamanca. Secundaria y bachillerato. Octaedro 2007).

También se observa esta tendencia a la definición frástica en las locuciones:

hora [...] 8 hora punta locución sustantiva Llamamos hora punta al espacio de tiempo en el que coinciden muchas personas entrando o saliendo de sus trabajos y se forman aglomeraciones en el transporte público y atascos en el tráfico. Si tienes que ir a Madrid en hora punta, sal un poco antes de lo habitual.

(Diccionario Estudio Salamanca. Secundaria y bachillerato. Octaedro 2007).

tromba 1 en tromba locución adverbial de modo Una corriente de agua o una multitud de personas o de cosas se mueven en tromba si surgen con fuerza y de repente: Los alumnos entraron en tromba en el despacho del director para pedir un día libre.

(Diccionario Estudio Salamanca. Secundaria y bachillerato. Octaedro 2007).

\section{COHERENCIA EN LA INFORMACIÓN ENCICLOPÉDICA}

Al margen de las necesarias flexibilidades, lo que sí conviene es reivindicar una coherencia en el procedimiento que se va a seguir y esto implica el establecimiento de sistematicidades a partir de un esquema trazado que calibre la utilidad de la información.

10 Por otra parte, se ha reconocido la imposibilidad de establecer en todos los casos conmutaciones entre definición y definido (Porto Dapena 2014).

11 Es la que Bosque (1982: 105-106) incluye, lógicamente, dentro de las definiciones impropias o metalingüísticas, formuladas en metalengua de signo, junto con las que se introducen mediante "dícese de", "aplícase a", y las que comienzan con secuencias como "relativo" o "perteneciente a". Todas ellas nunca cumplen la propiedad de la "sustituibilidad", o, lo que es lo mismo, no pueden reemplazar al definido en ningún contexto sintáctico. Empleando la terminología de Weinreich (1975), las llama implicativas o contextuales, sobre las que puntualiza que la palabra entrada se presenta dentro de su contexto de uso frecuente, de tal manera que la definición no es más que una ejemplificación. 
La búsqueda de precisión, pero también de una información completa para el usuario del diccionario implica que, en muchas ocasiones, se abunde en detalles a la hora de definir algunos vocablos, por lo que se hace gala del enciclopedismo. No obstante, parece que la deuda con un modelo de catalogación en la que el elemento de mayor extensión semántica se concreta únicamente con unas diferencias específicas muy ajustadas y suficientes para deslindar unidades de tratamiento propicia que se produzcan modificaciones muy relevantes de una edición a otra, que es lo que se percibe en el Diccionario académico, en las ediciones de 2001 y de 2014.

Es patente que el DLE (2014) tiende a aminorar la información enciclopédica. Está justificada esta decisión en no pocos ejemplos, porque la perífrasis sobrepasaba, con creces, la función distintiva de la pieza léxica:

reloj.

1. m. Máquina dotada de movimiento uniforme, que sirve para medir el tiempo o dividir el día en horas, minutos y segundos. Un peso, un muelle o una pila producen, por lo común, el movimiento, que se regula con un péndulo o un volante, y se transmite a las manecillas por medio de varias ruedas dentadas. Según sus dimensiones, colocación o uso, así el reloj se denomina de torre, de pared, de sobremesa, de bolsillo, de muñeca, etc.

(DRAE 2001)

Sin embargo, la reducción por la que se opta en 2014 deriva en una desmembración en dos acepciones. En la primera, se define genéricamente la entrada sin aludir a especificaciones diferenciales con respecto a posibles subtipos, lo que le permite comportarse, a su vez, como hiperónimo en otras voces, tal es el caso de sus hipónimos cronómetro o metrónomo. En la segunda, en cambio, se hace alusión a la combinación estable ${ }^{12}$ reloj mecánico mediante el destacado del sistema de envío. Precisamente, en el lugar correspondiente a dicha combinación se vuelven a detallar los mismos elementos que se tenían en cuenta en la edición anterior. En cualquier caso, no parece muy acertado, pues ni en el léxico general ni en el disponible resulta especialmente destacable su frecuencia de uso.

reloj

1. $\mathbf{m}$. Instrumento que sirve para medir el tiempo.

2. m. reloj mecánico.

$[\ldots]$

reloj mecánico

1. m. reloj en el que un peso, un muelle o una pila producen, por lo común, el movimiento, que se regula con un péndulo o un volante, y se transmite a las manecillas por medio de varias ruedas dentadas. Según sus dimensiones, colocación o uso, así el reloj se denomina de torre, de pared, de sobremesa, de bolsillo, de muñeca, etc.

(DLE 2014)

En otros casos, aun sin caer en hiperespecializaciones, se logra mayor precisión, sobre todo si tenemos en cuenta la necesidad de acudir, en la medida de lo posible, a la prototipicidad definitoria. Esto se percibe al comparar las definiciones de cuadro en la ediciones académicas de 2011 y 2014:

12 Así se la llama en las páginas preliminares del Diccionario académico. 
cuadro, dra.

[... ] 3. m. Lienzo, lámina, etc., de pintura.

$(($

DRAE 2001)

cuadro, dra [...] 3. m. Composición pictórica desarrollada sobre lienzo, madera, papel, etc., generalmente enmarcada.

DLE (2014).

No faltan ejemplos que requieren de alguna matización. Este es el caso de plato, pues al especificarse que es redondo parece excluir dentro de este vocablo los recipientes cuadrados, rectangulares u ovalados que tienen similares usos:

\section{plato}

1. m. Recipiente bajo y redondo, con una concavidad en medio y borde comúnmente plano alrededor, empleado en las mesas para servir los alimentos y comer en él y para otros usos. (DLE 2014)

Una simple precisión, como la incluida en el Diccionario CLAVE (2012), subsana el problema. Además, conviene incidir otra vez en la idea de la prototipicidad, pues, si bien un objeto puede tener tantos usos como se le pretende dar, en una paráfrasis definitoria deben establecerse las selecciones consabidas (los platos se emplean habitualmente para servir la comida). Por todo ello, la definición proporcionada por este repertorio parece más recomendable:

plato

1 Recipiente bajo, generalmente redondo, con una concavidad central más o menos honda, que se usa para servir las comidas: He fregado los platos y los he colocado en el escurridor.

(Diccionario CLAVE 2012)

Resulta, de todas formas, reseñable que este último diccionario no actúe siempre de la misma manera, en relación con la señalada prototipicidad. Así, en el caso de mantel, en la definición proporcionada, se excluye la posible pieza de plástico con que se cubre la mesa, por lo que parece más acertado, en este caso, el proceder académico:

\section{mantel}

s.m.

Pieza de tela con que se cubre la mesa durante la comida.

(Diccionario CLAVE 2012)

\section{mantel}

1. m. Cubierta de lino, algodón u otra materia, que se pone en la mesa para comer.

(DLE 2014)

En todo momento, han de tenerse en cuenta, como se ha apuntado, no solo las necesidades descodificadoras, sino también las orientadas a la producción de mensajes comunicativos. En el afán por apartar rasgos enciclopédicos y a la vez incorporar datos extralingüísticos tradicionalmente considerados de interés, contradicción nada extraña en la práctica 
definicional, se llega a conseguir, como se acaba de ver, una suerte de arbitrariedad selectiva poco rentable. En ese sentido, Gutiérrez Cuadrado (2008: 130-131), que defiende que las definiciones enciclopédicas ayudan al conocimiento del comportamiento léxico y gramatical de los vocablos, alude, con razón, a la falta de coherencia. Esto lo ejemplifica con las definiciones de los animales en las que se menciona, entre otros rasgos, el sonido que emiten. Esta información no es ni mucho menos homogénea, ya que, dentro de una misma catalogación lexicográfica, en unas ocasiones aparece y en otras no. Esta particularidad posee más importancia de lo que se cree, sobre todo si tenemos en cuenta que si entre el significante del animal y el de su voz hay afinidad combinatoria ${ }^{13}$, esta última ha de considerarse un rasgo definitorio, en la medida en que se quiera aprovechar la validez codificadora que también puede llegar a poseer el segundo enunciado microestructural.

En los casos en los que el definido comparte rasgos sémicos con otro u otros pertenecientes, por ejemplo, a la misma especie, lo deseable es llevar a cabo una selección homogénea de los elementos que conforman la diferencia específica. Por ello, un comportamiento arbitrario no solo merma los resultados óptimos que busca el diccionario, sino que priva al usuario de un conocimiento uniforme que le permita crear su mapa de relaciones conceptuales. Valgan las definiciones que se proporcionan para oveja y cabra en la última edición del repertorio académico. En el primer caso, no se especifica que se trata de un animal doméstico, aunque evidentemente lo es, y se hace referencia al hecho de que con su leche se hacen quesos; mientras que, en el segundo, sí se alude a su condición doméstica, pero no se señala nada sobre la elaboración del mismo producto alimenticio:

\section{oveja}

1. f. Mamífero rumiante de tamaño mediano, que posee lana y carne muy apreciadas, cuyo macho presenta cuernos arrollados en espiral y de cuya hembra se obtiene leche con la que se elaboran quesos.

(DLE 2014)

\section{cabra}

1. f. Mamífero rumiante doméstico, como de un metro de altura, muy ágil para saltar y subir por lugares escarpados, con pelo corto, áspero y a menudo rojizo, cuernos vueltos hacia atrás, un mechón de pelos largos colgante de la mandíbula inferior y cola muy corta. (DLE 2014)

Pese a que, en ocasiones, pueden observarse criterios de selección más equilibrados, no siempre se consigue una sistematicidad completa. En ese sentido, en el Diccionario de la lengua española. Primaria. Anaya-VOX (2013), las voces anteriores rentabilizan la coincidencia en algunos rasgos sémicos ${ }^{14}$ :

13 Resulta especialmente relevante que también se inserten en el segundo enunciado lexicográfico, en la medida de lo posible, y sobre todo si ayuda a la claridad del definido, datos sobre la combinatoria léxica; pues, en cierta medida, algunos vocablos incluyen entre sus rasgos sémicos el contenido de otro que ejerce de elemento determinante, tal como sucede en las solidaridades léxicas multilaterales en las que es posible generar oposiciones paradigmáticas, y que no son, al fin y al cabo, más que colocaciones, si bien, como es sabido, nocionalmente son de mayor extensión. Todo ello al margen de que en la información microestructural no definicional también se deba dar constancia de las posibles coapariciones frecuentes (Castillo Carballo 2015: 82-93).

14 Tanto en una como en la otra se habla de su carácter doméstico y de que de ambas se extraen productos comestibles, aunque no se expliciten de la misma forma. 
oveja

1 Animal mamífero doméstico hembra, con el cuerpo cubierto de abundante pelo, con el que después se fabrica lana. Vive en rebaños y su carne es comestible.

\section{cabra}

1 Animal mamífero con cuernos curvados hacia atrás y un mechón de pelos en la barbilla. Es fácil domesticarla y se aprovecha de ella la carne, la leche y la piel.

Igualmente, sería deseable que en los casos de variabilidad genérica mediante heteronimia las definiciones se ajustasen al criterio de la prototipicidad, no solo en cuanto a la selección de los rasgos diferenciadores, sino también en lo que implica evitar, en animales como la oveja, por ejemplo, (ya referida), que la paráfrasis definitoria se reduzca a la fórmula "hembra de", sin más. No cabe duda de que entre carnero y oveja esta última tiene entidad en sí misma para abandonar su suerte a los rasgos sémicos del primero en el que no se detecta una referencia recíproca. Eso es lo que ocurría en la edición del DRAE 2001:

oveja.

1. f. Hembra del carnero.

(DRAE 2001)

carnero1.

1. m. Mamífero rumiante, que alcanza de siete a ocho decímetros de altura hasta la cruz, con frente convexa, cuernos huecos, angulosos, arrugados transversalmente y arrollados en espiral, y lana espesa, blanca, negra o rojiza.

(DRAE 2001)

Sin embargo en el DLE 2014 no solo se explicita en la primera acepción una definición detallada de oveja (además de mantener en la segunda la fórmula "hembra de"), sino que en carnero se hace alusión expresa a esta, pues se dice, entre otras cosas, que es el 'macho de la oveja':

oveja

1. f. Mamífero rumiante de tamaño mediano, que posee lana y carne muy apreciadas, cuyo macho presenta cuernos arrollados en espiral y de cuya hembra se obtiene leche con la que se elaboran quesos. Un rebaño de ovejas.

2. f. Hembra de la oveja, por oposición al carnero.

(DLE 2014)

carnero1

1. m. Macho de la oveja, que alcanza de 70 a $80 \mathrm{~cm}$ de altura hasta la cruz, con frente convexa, cuernos huecos, angulosos, arrugados transversalmente y arrollados en espiral, y lana espesa, blanca, negra o rojiza. U. a veces para referirse a la especie.

(DLE 2014)

\section{LA DEFINICIÓN EN LOS DICCIONARIOS DIDÁCTICOS}

Lo señalado para los diccionarios generales resulta igualmente válido para los repertorios orientados a la enseñanza y aprendizaje de la lengua, independientemente de que se 
destinen a alumnos nativos o foráneos. En estos catálogos hay que incidir especialmente en la necesidad de hacer inteligibles las definiciones, por razones evidentes, aunque se pueden establecer diferencias marcadas por la idiosincrasia del alumno al que va destinado el repertorio, ya que, a veces, los intereses son distintos, en la medida en que los alumnos nativos pueden emplear el diccionario como una herramienta más dentro de su diseño curricular; de ahí que en las paráfrasis definitorias aparezcan vocablos característicos de materias muy determinadas, como las relativas al conocimiento del medio. Sin embargo, en el caso de los diccionarios para extranjeros, los intereses no tienen por qué coincidir a no ser que nos refiramos al español con fines específicos. En ese sentido, los repertorios monolingües de aprendizaje deben, especialmente, dar cuenta de definiciones con las que el usuario se sienta satisfecho y no le suponga un sobreesfuerzo que le obligue a abandonar la búsqueda, porque le resulte baldía. Así el Diccionario para la enseñanza de la lengua española, VOX-Universidad de Alcalá 1995, muy acertadamente, emplea un número determinado de definidores, siempre y cuando le sea posible, que garantiza, al menos, la compresión a los aprendices de un nivel de conocimiento léxico intermedio. Sin lugar a dudas, este modo de proceder redunda en la adecuación de las necesidades del destinatario (García Platero 2010: 175-179), que ve cumplidas sus expectativas, como se percibe en estos ejemplos:

sar·tén $[\ldots] f$. Recipiente redondo, ancho, poco profundo, de fondo plano y con un mango largo, que se usa para freír: echó dos huevos en la $\sim$.

pa·e·lla $[\ldots]$ 1. $f$. Comida hecha con arroz, al que se añaden *mariscos, carne, pescado y otros alimentos: la $\sim$ es el plato más típico de Valencia.

pis·to $[\ldots] \boldsymbol{m}$. Comida hecha con hortalizas picadas en trozos muy pequeños que se fríen y luego se cocinan lentamente: no podemos hacer $\sim$ porque nos faltan los calabacines y el pimiento.

Dejando a un lado este tipo de repertorios orientados a aprendices no nativos, cabe tener en cuenta también la prototipicidad definicional, a la que antes se aludía para los catálogos generales. En el caso de los diccionarios escolares, sobre todo los orientados a los ciclos de aprendizaje iniciales, se percibe una lógica adaptación de los prototipos de acuerdo con la realidad más inmediata del usuario:

\footnotetext{
gnomo

1 Ser imaginario muy pequeño que vive en los bosques y que tiene poderes mágicos. Se suelen representar con un gorro en forma de cucurucho.

(Diccionario de la Lengua española. Primaria. Anaya-VOX 2013).

\section{gnomo}

Personaje fantástico muy pequeño que aparece en muchos cuentos infantiles y suele ser simpático.

(Diccionario Júnior. Educación Primaria. Vicens Vives 2001).
}

Se ha dicho antes también que la definición debe ser lo más objetiva posible. Sin embargo, en algún diccionario de este tipo, a veces, se puede llegar a complementar la diferencia 
específica de carácter enciclopédico con pautas de conducta o consejos para los alumnos de estos niveles, con el fin de orientarlos hacia determinados hábitos considerados recomendables. Podría pensarse que estas sugerencias son prescindibles, pero, en cierto modo, también contribuyen a poner en uso, como si de un ejemplo se tratase, el definido.

\author{
dieta \\ 1 Conjunto de normas o guías referidas al tipo, la cantidad y la combinación de alimentos \\ que come una persona o una comunidad de personas. La dieta mediterránea se caracteriza \\ por una abundancia de alimentos frescos: El médico le recomendó una dieta basada en \\ las verduras. \\ (Diccionario de la Lengua española. Primaria. Anaya-VOX 2013). \\ marranada \\ 1 Cosa o acción muy sucia o poco educada. No lavarse las manos antes de comer es una \\ marranada. \\ (Diccionario de la Lengua española. Primaria. Anaya-VOX 2013)

\section{manosear} \\ 1 Tocar una cosa con las manos muchas veces. No se deben manosear los alimentos. \\ (Diccionario de la Lengua española. Primaria. Anaya-VOX 2013)

\section{madrugar} \\ 1 Levantarse muy pronto por la mañana en especial antes de que salga el Sol. Las personas \\ mdrugamos para ir al trabajo o al colegio. \\ (Diccionario de la Lengua española. Primaria. Anaya-VOX 2013)
}

Al mismo tiempo no escasean en otros repertorios didácticos ejemplificaciones con finalidades similares. Véanse estos dos ejemplos:

\title{
dieta
}

1 conjunto de los alimentos que come o que puede comer una persona: una dieta sana debe ser variada; el médico le ha puesto una dieta sin grasas ni dulces.

(Diccionario Júnior. Educación Primaria. Vicens Vives 2001) ${ }^{15}$.

\section{golosina}

Cosa dulce que se come más para disfrutar que para alimentarse: el abuso de golosinas perjudica la dentadura.

(Diccionario Júnior. Educación Primaria. Vicens Vives 2001.)

No faltan tampoco casos de hipoespecialización, sobre todo en diccionarios infantiles. Aunque resulte compresible que en estos repertorios se cuente con un número muy restringido de entradas, también lo es que las definiciones sean breves. Sin embargo, la brevedad puede caer en la ausencia de elementos definidores que ayuden a identificar las entidades que se abordan, por mucho que en otros artículos referentes a voces que pertenecen al mismo campo semántico sí se recurra a datos complementarios que configuren una diferencia

15 Contrástese este artículo con el citado anteriormente del Diccionario de la Lengua española. Primaria. AnayaVOX 2013, en el que la recomendación forma parte de la paráfrasis definitoria. 
específica suficiente para los destinatarios. Compárese, por ejemplo, el caso de frambuesa frente a fresa y cereza, incluido en Mi primer diccionario Larousse 2011:

frambuesa Una frambuesa es un fruto pequeño y rojo que crece en el campo. Con las frambuesas se hace mermelada.

fresa Una fresa es un fruto pequeño de color rojo. Es dulce y tiene forma de corazón. Los fresones son más grandes que las fresas pero igual de sabrosos.

cereza La cereza es una fruta pequeña de color rojo oscuro, y con un hueso en el centro. Las cerezas maduran en primavera y crecen en el cerezo.

\section{A MODO DE CONCLUSIÓN}

No les falta razón a quienes afirman que definir es una de las tareas más complejas a las que se tiene que enfrentar el lexicógrafo. Sin embargo, esta dificultad no viene dada por la imposibilidad de delimitar con rigor y verbalizar algo tan inefable como el significado, pues este anhelo está muy lejos de conseguirse, bien lo saben los semánticos. Pero el autor de diccionarios tampoco ha de pretender subsanar estos problemas, pues no le corresponde. Su función es otra, y tiene que ver con las propias características de un producto orientado a usuarios muy distintos, con necesidades y carencias ciertamente variadas, pero que, en todo caso, busca entender los sentidos consolidados de una lengua en una sincronía dada.

En las paráfrasis definicionales, junto con la voz hiperonímica se añaden unas diferencias específicas que han de incluir los rasgos que se consideran más válidos para identificar suficientemente la unidad de la que se está informando. El rigor en el tratamiento de estos rasgos de contenido no puede ser incompatible con la necesaria inteligibilidad, si se pretende que la consulta aporte los frutos adecuados. Por esta razón, es imprescindible obrar sin dogmas, aunque se aprovechen las aportaciones metalexicográficas y se tengan en cuenta los avances experimentados por otras disciplinas. Se trata precisamente de un reto en la confección de futuros diccionarios.

Cabe puntualizar que, en ningún modo, han de desecharse datos referentes al conocimiento de la realidad extralingüística, por mucho que sean ajenos al ámbito del significado, pues pueden aportar una información muy útil que abunden en la necesaria estereotipicidad. $\mathrm{Y}$ es que no hay que olvidar que nos encontramos con un proceso de síntesis de rasgos muy diversos. Conviene abogar por una mayor sistematización a la hora de seleccionar los datos en las llamadas definiciones enciclopédicas (aunque en el fondo, la mayor parte de las veces, nos encontramos con paráfrasis de carácter mixto). No basta con acumular, de forma arbitraria, informaciones heterogéneas nada útiles para la correcta descodificación de la pieza léxica, si bien tampoco se puede olvidar la función codificadora del segundo enunciado microestructural.

El esfuerzo para conseguir una definición que se ajuste a las necesidades del usuario es aún más necesario en la elaboración de catálogos de carácter didáctico, tanto en los orientados a la enseñanza y aprendizaje de la lengua nativa como en los de una segunda lengua, pues la competencia léxica del usuario al que van destinados así lo exige.

No son desdeñables las incoherencias o deficiencias que se han podido observar en el segundo enunciado y que requieren de un análisis y reflexión por parte del lexicógrafo. Solo 
si este comprende que su misión es la de elaborar herramientas de utilidad para los lectores, al margen de los intereses de las diferentes escuelas lingüísticas, podrá abordar el problema de la definición sin prejuicios y con la requerida eficacia.

\section{Referencias bibliográficas}

Abad Nebot, F. (1999). "El diccionario como género literario". En Carbonero Cano, P., M. Casado Velarde y P. Gómez Manzano (eds.). Lengua y discurso. Estudios dedicados al profesor Vidal Lamíquiz. Madrid: Arco Libros, pp. 45-58.

Ahumada, I. (2006). "Justificación lingüística de las insuficiencias que presentan los actuales diccionarios de lengua”. En Moya Corral, J. A. y M. Sosinski (eds.). Lexicografía y enseñanza de la lengua española. Granada: Universidad de Granada, pp. 16-32.

Anaya Revuelta, I. (1996). "Análisis de los rasgos no pertinentes en las definiciones del diccionario de la RAE”, Español Actual, 66, pp. 67-77.

Anaya Revuelta, I. (1999-2000). "Los diccionarios enciclopédicos del español actual”, Revista de lexicografia, 6, pp. 7-36.

Bosque, I. (1982). "Sobre la definición lexicográfica", Verba, 9, pp. 105-123.

Castillo Carballo, M. ${ }^{a}$ A. 2015. De la investigación fraseológica a las decisiones fraseográficas. Un estudio de interrelaciones. Vigo: Editorial Academia del Hispanismo.

Climent de Benito, J. (2007). El diccionario como producto lexicográfico. Diccionarios de lengua. La enciclopedia, Madrid: Liceus, E-Excellence.

Coseriu, E. (1977). Principios de semántica estructural. Madrid: Gredos.

Dagenais, L. (1985). "Le problème de la description sémantique en lexicographie. Les vocables français: permettre, défendre, autoriser, interdire", Cahiers de lexicologie, 46, pp. 57-107.

Dubois, J y Cl. Dubois (1971). Introduction à la lexicographie. Le dictionnaire. París: Larousse.

Escobedo Rodríguez, A. (1999). "Léxico estructurado y léxico nomenclador". En Carbonero Cano, P., M. Casado Velarde y P. Gómez Manzano (eds.). Lengua y discurso. Estudios dedicados al profesor Vidal Lamíquiz. Madrid: Arco Libros, pp. 279-286.

García Ibáñez, D. (2001). "El diccionario como género literario”, EPOS, XVII, pp. 71-87.

García Platero, J. M. (2010). "La información semántica en los diccionarios de aprendizaje”. En Ruhstaller, S. y M. D. Gordón (eds.). Diccionario y aprendizaje del español. Bern: Peter Lang, pp. 171-184.

García Platero, J. M. (2015). La innovación léxica en español. Perspectivas de análisis. Vigo: Editorial Academia del Hispanismo.

González Pérez, R. (1992). "Consideraciones metodológicas sobre la elaboración de diccionarios monolingües del español”. Revista de Filología de la Universidad de La Laguna, 11, pp. 79-101.

Gutiérrez Cuadrado, J. (2008). "Desafíos de la definición". En DeCesaris, J. A. y E. Bernal (coords.). Proceedings of the XIII EURALEX International Congress, Barcelona: Universitat Pompeu Fabra, pp. 525-533.

Gutiérrez Cuadrado, J. (2010). "Niveles y procesos en la definición del diccionario", Quaderns de Filologia. Estudis lingüistics, XV, pp. 121-138.

Haiman, J. (1980). "Dictionnaires and Enciclopedias", Lingua, 50, pp. 329-357.

Hernández, H. (1989-90). "Semántica, lexicografía y otras cuestiones conexas", Revista de Filología de la Universidad de La Laguna, 8-9, pp. 175-182.

Porto Dapena, J.-Á. (2014). La definición lexicográfica. Madrid: Arco Libros.

Pottier, B. (1977). Lingüistica general. Madrid: Gredos.

Quemada, B. (1987). "Notes sur Lexicographie et Dictionnairique", Cahiers de Lexicologie, 51, pp. 229-242.

Rastière, F. (1987). Sémantique interprétative. París: Puf. 
Rastière, F. (1991). Sémantique et recherches cognitives. París: Puf.

Rey, A. (1989). "Le Français et les dictionnaires, aujourd'hui”. En Helmy Ibrahim, A. (dir.) Le français dans le Monde. Recherches et applications: Lexiques. París: Hachette, pp. 6-17.

Rey-Debove, J. (1994). "La lexicografía moderna", Voz y Letra, V/1, pp. 31-45.

Rodríguez Barcia, S. (2016). Introducción a la lexicografía. Madrid: Síntesis.

Seco, M. (1987). "Problemas formales de la definición". En Estudios de lexicografía española. Madrid: Paraninfo, pp. 217-240.

Tarp, S. (2003): “Two opposing theories: On H.E. Wiegand's Recent Discovery of Lexicographic Functions", Hermes. Journal of Linguistics, 31, pp. 171-196.

Tarp, S. (2008): Lexicography in the Borderland between Knowlegde and Non-Knowlegde, Tübingen: Max Niemeyer Verlag.

Tarp, S. (2013). "Necesidad de una teoría independiente de la lexicografía: el complejo camino de la lingüística teórica a la lexicografía práctica", Clac. Círculo de lingüística aplicada a la comunicación, 56, pp. 110-154.

Tesso, E. de (1987). "En torno a la definición lexicográfica", Contextos, V, 10, pp. 29-56.

Trujillo, R. (1984). "Algunas observaciones sobre el lenguaje poético”, Liminar, 18-19, pp. 27-45.

Trujillo, R. (1994). "El diccionario frente a la semántica”. En Hernández, H. (coord.). Aspectos de lexicografía contemporánea. Barcelona: Biblograf, pp.73-93.

Trujillo, R. (1995). “Algunos problemas semánticos de la lexicografía”. En Fernández-Barrientos Martín, J. y C. Wallhead (eds.): Temas de lingüistica aplicada. Granada: Universidad de Granada, pp. 81-104.

Weinreich, V. (1975).“Lexicographic Definition and Descriptive Semantics”. En Householder, F. W. y S. Saporta (eds.). Problems in Lexicography. Bloomington: Indiana University, pp. 25-43.

\section{Diccionarios:}

Clave. Diccionario de uso del español actual (2012). Madrid: SM.

Diccionario Estudio Salamanca. Secundaria y Bachillerato (2007). Barcelona: Octaedro.

Diccionario júnior. Educación Primaria (2001). Barcelona: Vicens Vives

Diccionario para la enseñanza de la lengua española (1995). Vox-Biblograf-Universidad de Alcalá de Henares, Barcelona, 1995.

Diccionario Primaria. Lengua española. Anaya VOX (2013). Barcelona: Larousse Editorial.

Mi primer diccionario Larousse (2011). Barcelona: Larousse.

Real Academia Española (2001). Diccionario de la lengua española. Madrid: Santillana. (DRAE).

Real Academia Española (2014). Diccionario de la lengua española. Madrid: Santillana. (DLE). 